\title{
Mechanisms underlying effects of nocturnal ventilation on daytime blood gases in neuromuscular diseases
}

\author{
D. Annane*, M.A. Quera-Salva*, F. Lofaso*, J.B. Vercken*, O. Lesieur*, C. Fromageot ${ }^{\S}$, B. Clair*, \\ P. Gajdos*, J.C. Raphael*
}

Mechanisms underlying effects of nocturnal ventilation on daytime blood gases in neuromuscular diseases. D. Annane, M.A. Quera-Salva, F. Lofaso, J.B. Vercken, O. Lesieur, C. Fromageot, B. Clair, P. Gajdos, J.C. Raphael. (C)ERS Journals Ltd 1999.

ABSTRACT: The hypothesis that, in neuromuscular and chest wall diseases, improvement in central respiratory drive explains the effects of night-time ventilation on diurnal gas exchanges was tested.

The effects at 6 months, 1, 2 and 3 yrs of intermittent positive pressure ventilation (IPPV) on arterial blood gas tension, pulmonary function, muscle strength, sleep parameters, respiratory parameters during sleep and ventilatory response to $\mathrm{CO}_{2}$ were evaluated in 16 consecutive patients with neuromuscular or chest wall disorders.

As compared with baseline, after IPPV daytime arterial oxygen tension $\left(\mathrm{Pa}_{\mathrm{a}} \mathrm{O}_{2}\right)$ increased $\left(+2.3 \mathrm{kPa}\right.$ at peak effect) and arterial carbon dioxide tension $\left(\mathrm{Pa}_{\mathrm{a}} \mathrm{CO}_{2}\right)$ and total bicarbonate decreased $\left(-1.8 \mathrm{kPa}\right.$ and $-5 \mathrm{mmol} \cdot \mathrm{L}^{-1}$, respectively) significantly; vital capacity, total lung capacity, maximal inspiratory and expiratory pressures and alveolar-arterial oxygen gradient did not change; the apnoea-hypopnoea index and the time spent with an arterial oxygen saturation $\left(\mathrm{S}_{\mathrm{a}}, \mathrm{O}_{2}\right)$ value $<90 \%$ decreased $(-24$ and $-101 \mathrm{~min}$, respectively), sleep efficiency and mean $\mathrm{S}_{\mathrm{a}}, \mathrm{O}_{2}$ increased $(+16 \%$ and $+5 \%$, respectively); and ventilatory response to $\mathrm{CO}_{2}$ increased $\left(+4.56 \mathrm{~L} \cdot \mathrm{min}^{-1} \cdot \mathrm{kPa}^{-1}\right)$ significantly. The reduction in $\mathrm{Pa}_{\mathrm{a}} \mathrm{CO}_{2}$ observed after IPPV correlated solely with the increase in the slope of ventilatory response to the $\mathrm{CO}_{2}$ curve $(\mathrm{r}=-0.68, \mathrm{p}=0.008)$.

In neuromuscular or chest wall diseases, improvement of daytime hypoventilation with nocturnal intermittent positive pressure ventilation may represent an adaptation of the central chemoreceptors to the reduction of profound hypercapnia during sleep or reflect change in the quality of sleep.

Eur Respir J 1999; 13: 157-162.

Nocturnal intermittent positive pressure ventilation (IPPV) results in improved chronic hypoventilation during daytime spontaneous ventilation in patients with neuromuscular or chest-wall diseases [1-6] and chronic obstructive pulmonary disease (COPD) [7]. In COPD, this improvement has usually been attributed to improved respiratory muscle strength [8-11] (see however, ElLIOTT et al. [12]), rather than to an increase in ventilatory response to $\mathrm{CO}_{2}$ [12]. Because numerous studies $[1,6,13]$ provided evidence that in neuromuscular diseases nocturnal IPPV did not affect respiratory muscle strength, it appears that mechanisms for the improvement of diurnal arterial blood gases with nocturnal IPPV are different in these patients than in COPD patients. Therefore, an improvement in lung mechanics with IPPV in neuromuscular or chest wall diseases could account for an improvement in arterial blood gases. However, although slight increases in lung volumes have been reported $[1,14]$, it seems more likely that nighttime IPPV has no significant effect on lung compliance $[6$, 15]. The last possible mechanism may be an improvement in central respiratory drive. The explanation could be a reduction of an exposure of the central chemoreceptors to profound hypercapnia during sleep and a possible relief of sleep deprivation with nocturnal IPPV, which both would increase the carbon dioxide sensitivity.
*Service de Réanimation Médicale; ${ }^{\S}$ Service de Physiologie-Exploration Fonctionnelles, hôpital Raymond Poincaré, Faculté de Médecine Paris Ouest, Garches, France; ServicedePhysiologie-ExplorationsFonctionnelles - Unité INSERM U 296, hôpital Henri Mondor, Créteil, France.

\section{Correspondence: D. Annane}

Service de Réanimation Médicale

hôpital Raymond Poincaré

Faculté de Médecine Paris Ouest

104 boulevard Raymond Poincaré

92380 Garches

France

Fax: 33147107783

Keywords: Central drive

hypoventilation

neuromuscular

night-time ventilation

Received: November 71997

Accepted after revision August 131998
Therefore, to understand the mechanisms by which hypercapnia is improved by IPPV in neuromuscular or chest wall disorders, the effect of long-term night-time IPPV was evaluated on arterial blood gas tension, pulmonary function, muscle strength, sleep parameters, respiratory parameters during sleep and ventilatory response to $\mathrm{CO}_{2}$ in patients with neuromuscular or chest wall disorders.

\section{Methods}

\section{Study population}

Adult patients were eligible, after verbal informed consent was obtained, if they had neuromuscular and/or chest wall-related stable chronic alveolar hypoventilation and required nocturnal IPPV through tracheostomy or nasal mask. Exclusion criteria included no ventilator-free time, rapidly progressive disease (i.e. Duchenne muscular dystrophy or amyotrophic lateral sclerosis), and chronic obstructive lung disease.

\section{Pulmonary function tests}

Patients were always studied in the morning, in the sitting position and breathing room air. Pulmonary function 
tests were obtained after a 2-week period of stability. Forced spirometry (PK Morgan; Gillingham, Kent, UK) was measured according to the American Thoracic Society recommendations [16], lung volumes by the helium dilution technique (PK Morgan), and maximal inspiratory (MIP) and expiratory (MEP) pressures following the method of BLACK and HyATT [17]. Blood gases were obtained from an arterial sample while the patient was at rest in the sitting position and breathing room air (ABL 330; Radiometer; Copenhagen, Denmark). The alveolar-arterial pressure difference for oxygen $\left(\mathrm{PA}-\mathrm{a}, \mathrm{O}_{2}\right)$ was calculated according to the standard formula, assuming a respiratory quotient value of 0.8 .

\section{Ventilatory responses to carbon dioxide}

Patients were always studied in the morning and had been in the fasting state for at least $12 \mathrm{~h}$. The ventilatory response to hypercapnia was determined by a modified method described by ADLER [18] based on the original concept of Read [19]. The initial breathing gas mixture was $5 \% \mathrm{CO}_{2}$ in oxygen. Subjects remained in the sitting position and breathed room air through the mouthpiece for almost 5 min to achieve a steady state for end tidal carbon dioxide tension $\left(P \mathrm{ET}, \mathrm{CO}_{2}\right)$. Thereafter patients began rebreathing for $4 \mathrm{~min}$. The $\mathrm{CO}_{2}$ fractions $\left(\mathrm{FCO}_{2}\right)$ in respiratory air (Infrared analyser; Gould, Ballainvilliers, France) were measured in the breathing tube, close to the lips. The variables determined breath-by-breath during the rebreathing period were total respiratory duration (ttot), tidal volume $(V \mathrm{~T})$, and $\mathrm{CO}_{2}$ fraction $\left(F \mathrm{ET}, \mathrm{CO}_{2}\right)$ as the end-tidal value. From these values, the following were calculated breathby-breath: respiratory frequency, $(f \mathrm{R}=1 /$ tot $)$, total minute ventilation $\left(V^{\prime} \mathrm{E}=\mathrm{R} \times V \mathrm{~T}\right)$. Records were analysed by plotting $V^{\prime} \mathrm{E}$ against $P \mathrm{ET}, \mathrm{CO}_{2}$. The resulting plots were linear and therefore were analysed by fitting the data to the following equation:

$$
V^{\prime} \mathrm{E}=\mathrm{S}\left(P \mathrm{ET}_{,} \mathrm{CO}_{2}-\beta\right)
$$

where $\mathrm{S}$ is the slope of $V^{\prime} \mathrm{E}$ versus $P \mathrm{ET}, \mathrm{CO}_{2}$ and $\beta$ the intercept on the $P \mathrm{ET}, \mathrm{CO}_{2}$ axis when $V^{\prime} \mathrm{E}=0$. In each patient the mean slope of $V^{\prime} \mathrm{E}$ versus $P \mathrm{ET}, \mathrm{CO}_{2}$ and the mean $V^{\prime} \mathrm{E}$ corresponding to a $P \mathrm{ET}, \mathrm{CO}_{2}$ at $8 \mathrm{kPa}$, from three consecutive $\mathrm{CO}_{2}$ response curves (at 30 -min intervals) were obtained.

\section{Sleep studies}

The polysomnographic recording included electroencephalography(EEG)(C4-A1 and C3-A2 derivations), electrooculography, chin electromyography, electrocardiography (ECG), oronasal flow by thermistors, thoracic and abdominal movements by noncalibrated inductive plethysmography (Respitrace; Ardsley, NY, USA), and arterial oxygen saturation $\left(\mathrm{Sa}_{\mathrm{a}} \mathrm{O}_{2}\right)$ by finger pulse-oximetry (Biox Ohmeda 3700; Columbia, MD, USA). Sleep and sleep stages were scored according to the criteria of RECHTSCHAFFEN and KALES [20]. Apnoea was defined by the absence of airflow both at the nose and mouth for at least $10 \mathrm{~s}$. Hypopnoea was defined by the reduction in airflow (for at least $10 \mathrm{~s}$ ), of at least $50 \%$ of baseline, associated with a decrease in $\mathrm{Sa}, \mathrm{O}_{2}$ of $>4 \%$ of the preceding baseline [21]. Apnoea were considered obstructive when thoracic or abdominal movements were present, and central when these movements were absent. From raw data, the respiratory disturbance index (RDI) defined as the ratio of number of apnoeas plus hypopnoea/total sleep time (TST) in hours, and the sleep efficiency (SE) defined as the ratio TST $\times 100 /$ (total sleep period) were calculated.

\section{Intermittent positive pressure ventilation implementation}

All patients were ventilated using a volume-cycled portable ventilator (Monnal D, CFPO, Meudon la Foret, France or Eole 2A, SAIME Electronique, Savigny le Temple, France). Ten patients were treated by nasal IPPV with a home-made or manufactured (Respironics, Murrysville, PA, USA or ResMed Ventilator Mask System, Abington, UK) nasal masks, in two and eight cases, respectively. The remaining patients had to be tracheostomized for severe swallowing dysfunction (one case) or nasal mask-related complications (i.e. nasal bridge ulcerations in three cases). In all cases, IPPV was initiated at the hospital during the daytime. All patients were ventilated in the assist/control mode with a respiratory rate adjusted to the patient's spontaneous breathing frequency and an initial $V$ T adjusted at $10 \mathrm{~mL} \cdot \mathrm{kg}^{-1}$. Exhaled $V$ T measurements allowed adaptation of $V \mathrm{~T}$ to compensate for leaks in patients with nasal IPPV. None of the patients received oxygen therapy. Patients were discharged from the hospital when arterial carbon dioxide tension $\left(\mathrm{Pa}_{\mathrm{a}}, \mathrm{CO}_{2}\right)$ (during IPPV) was $<6 \mathrm{kPa}$ and adequate oxygenation during night-time was confirmed by oximetry monitoring.

\section{Patient follow-up}

All patients were followed-up at the outpatient clinic. The office follow-up included twice yearly reviewing of symptoms and physical signs, and seeking evidence of recurrent symptoms of hypoventilation. Pulmonary function tests, arterial blood gas, ventilatory response to $\mathrm{CO}_{2}$ tests were obtained at 6 months, 1, 2 and 3 yrs and sleep studies at 1 and 3 yrs after IPPV

\section{Statistical analysis}

Results are expressed as mean $\pm \mathrm{SD}$. For quantitative variables, baseline values were compared with follow-up measurements using analysis of variance (ANOVA) for repeated measures, completed by Bonferroni tests when needed. The relationship between the maximum variation of diurnal $\mathrm{Pa}_{\mathrm{a}} \mathrm{CO}_{2}$ and the maximum variation of the slope of the rebreathing test was assessed by linear regression analysis.

\section{Results}

\section{Patient characteristics}

Sixteen consecutive patients meeting the criteria for eligibility in the study were followed-up. One myasthenic patient was excluded because of a rapid deterioration of respiratory function and another patient with idiopathic scoliosis was lost during follow-up. The demographic and anthropometric characteristics, diagnosis and home ventilation techniques and duration are shown for the 14 remaining patients in table 1 . Six patients had stable idiopathic or postpolio (one case) scoliosis. Seven patients presented with myopathy, i.e. myotonic dystrophy (two), maltase acid deficiency (two), Becker muscular dystrophy (one) and unknown myopathy (two). Finally, one patient 
Table 1. - Demographic data of 14 patients with neuromuscular or chest wall diseases

\begin{tabular}{lcccccc}
\hline $\begin{array}{l}\text { Pt } \\
\text { No. }\end{array}$ & Diagnosis & $\begin{array}{c}\text { Sex } \\
\text { Age } \\
\text { yr }\end{array}$ & $\begin{array}{c}\text { Weight } \\
\text { kg }\end{array}$ & $\begin{array}{c}\text { Height } \\
\mathrm{cm}\end{array}$ & $\begin{array}{c}\text { Ventilation } \\
\text { techniques }\end{array}$ \\
\hline 1 & Myo. & M & 59 & 80 & 180 & Nasal mask \\
2 & Myo. & M & 44 & 90 & 165 & Nasal mask \\
3 & Myo. & M & 56 & 63 & 170 & Tracheostomy \\
4 & Myas. & F & 50 & 62 & 150 & Nasal mask \\
5 & Scol. & M & 65 & 50 & 150 & Tracheostomy \\
6 & Myo. & M & 25 & 65 & 167 & Tracheostomy \\
7 & Scol. & F & 61 & 55 & 142 & Nasal mask \\
8 & Scol. & F & 47 & 46 & 126 & Nasal mask \\
9 & Myo. & M & 57 & 85 & 169 & Nasal mask \\
10 & Myo. & F & 54 & 59 & 168 & Nasal mask \\
11 & Scol. & M & 40 & 43 & 165 & Nasal mask \\
12 & Scol. & M & 61 & 60 & 165 & Nasal mask \\
13 & Scol. & M & 49 & 98 & 180 & Tracheostomy \\
14 & Myo. & M & 48 & 77 & 180 & Nasal mask \\
\hline
\end{tabular}

Pt: patient; Myo.: myopathy; Myas.: myasthenia; Scol.: scoliosis; M: male; F: female.

had diaphragmatic paralysis as a sequaele of myasthenia gravis. All patients had moderate to severe ventilatory restriction, with vital capacity ranging $11-68 \%$ predicted $(38 \pm 17 \%$, mean \pm SD $)$ and total lung capacity ranging 22 $69 \%$ pred $(46 \pm 16$, mean \pm SD) (table 2$)$. They had chronic alveolar hypoventilation with diurnal $\mathrm{Pa}_{\mathrm{a}} \mathrm{CO}_{2}$ ranging 6.5$9.9 \mathrm{kPa}(7.3 \pm 0.9$, mean $\pm \mathrm{SD})$, arterial oxygen tension $\left(\mathrm{Pa}_{\mathrm{a}} \mathrm{O}_{2}\right)$ ranging $6.5-9.7 \mathrm{kPa}(8.1 \pm 1.1$, mean $\pm \mathrm{SD})$, and $\left[\mathrm{HCO}_{3}{ }^{-}\right]$ ranging $28-36 \mathrm{mmol} \cdot \mathrm{L}^{-1}(32 \pm 2$, mean $\pm \mathrm{SD})$. Finally, patients had reduced MIP from 26 to $64 \%$ pred (45 $21 \%$, mean \pm SD), MEP from 17 to $91 \%$ pred $(51 \pm 34 \%$, mean \pm SD $)$ and static transdiaphragmatic pressures from 0 to $5.3 \mathrm{kPa}$ $(1.7 \pm 1.9, \mathrm{n}=12$, mean $\pm \mathrm{SD})$.
Table 3. - Polysomnographic results at baseline and while receiving nocturnal intermittent positive pressure ventilation

\begin{tabular}{lccccl}
\hline & Baseline & $1 \mathrm{yr}$ & 3 yrs & F & p-value \\
\hline TST min & $294 \pm 95$ & $340 \pm 90$ & $336 \pm 56$ & 1.30 & 0.28 \\
RDI & $27 \pm 19$ & $3 \pm 7 * *$ & $2 \pm 6$ & 17.9 & 0.001 \\
$\mathrm{~S} 1+\mathrm{S} 2 \%$ & $69 \pm 6$ & $62 \pm 17$ & $62 \pm 13$ & 2.39 & 0.13 \\
$\mathrm{~S} 3+\mathrm{S} 4 \%$ & $11 \pm 6$ & $20 \pm 7 *$ & $20 \pm 10$ & 5.36 & 0.01 \\
$\mathrm{REM} \%$ & $15 \pm 6$ & $17 \pm 6$ & $20 \pm 5$ & 2.75 & 0.09 \\
$\mathrm{SE} \%$ & $74 \pm 10$ & $87 \pm 7^{* *}$ & $90 \pm 8$ & 29.1 & 0.001 \\
$\mathrm{Sa}_{\mathrm{a}} \mathrm{O}_{2}<90 \%$ min & $102 \pm 94$ & $13 \pm 26^{* *}$ & $1 \pm 2 *$ & 4.78 & 0.002 \\
Mean $\mathrm{Sa}_{2} \%$ & $89 \pm 3$ & $93 \pm 3_{2}^{* *}$ & $94 \pm 2$ & 9.52 & 0.002 \\
Minimal $\mathrm{Sa}_{\mathrm{a}} \mathrm{O}_{2} \%$ & $68 \pm 14$ & $80 \pm 14^{* *}$ & $88 \pm 4$ & 5.96 & 0.01 \\
\hline
\end{tabular}

TST: total sleep time; RDI: respiratory disturbance index; $\mathrm{S} 1+$ $\mathrm{S} 2$ and S3+S4: percentage of TST spent in sleep stage $1+2$ and $3+4$, respectively; REM: percentage of TST spent while in rapid eye movement (REM) phase; $\mathrm{Sa}_{\mathrm{a}} \mathrm{O}_{2}<90 \%$ : percentage of TST spent with an arterial oxygen saturation $\left(\mathrm{Sa}_{2} \mathrm{O}_{2}\right)$ below $90 \%$; SE: sleep efficiency. $*$ : $\mathrm{p}<0.05 ; * *: \mathrm{p}<0.01$ (Bonferroni tests)

All patients had decreased ventilatory response to $\mathrm{CO}_{2}$ with a slope ranging $0(\mathrm{n}=2)$ to $3.4 \mathrm{~L} \cdot \mathrm{min}^{-1} \cdot \mathrm{kPa}^{-1}(1.33 \pm$ 0.94 , mean \pm SD) (table 2).

Regarding baseline polysomnographic data (table 3), all patients had major respiratory events during sleep with an RDI ranging 15-85 $(27 \pm 19$, mean \pm SD $)$, prolonged time of oxygen desaturation below $90 \%$ (42-345 $\min 102 \pm 94$, mean $\pm \mathrm{SD})$, decreased mean $\mathrm{Sa}_{\mathrm{a}} \mathrm{O}_{2}(86-92 \%, 89 \pm 3 \%$, mean $\pm \mathrm{SD})$ and minimal $\mathrm{Sa}_{2} \mathrm{O}_{2}(49-80 \%, 67 \pm 12 \%$, mean $\pm \mathrm{SD})$. Apnoeas were of both types and predominantly of the central type $(76 \pm 10 \%$, mean \pm SD). The high percentage of TST spent in sleep stages 1 and $2(59-79 \%, 68 \pm 14 \%$, mean $\pm \mathrm{SD}$ ) with a shortening of the duration of sleep stages

Table 2. - Respiratory function before and after nocturnal intermittent positive pressure ventilation in 14 patients with neuromuscular or chest wall diseases

\begin{tabular}{|c|c|c|c|c|c|c|c|}
\hline & Baseline & 6 months & $1 \mathrm{yr}$ & $2 \mathrm{yrs}$ & $3 \mathrm{yrs}$ & $F$ & p-value \\
\hline VC mL & $1457 \pm 719$ & $1460 \pm 650$ & $1471 \pm 781$ & $1457 \pm 767$ & $1407 \pm 8.05$ & 0.41 & 0.80 \\
\hline VC $\%$ pred & $38 \pm 17$ & $47 \pm 24$ & $43 \pm 20$ & $41 \pm 20$ & $43 \pm 23$ & & \\
\hline $\mathrm{RV} \mathrm{mL}$ & $1227 \pm 437$ & $1165 \pm 387$ & $1180 \pm 290$ & $1170 \pm 236$ & $1154 \pm 277$ & 0.11 & 0.98 \\
\hline RV \% pred & $65 \pm 19$ & $65 \pm 22$ & $65 \pm 16$ & $62 \pm 11$ & $61 \pm 19$ & & \\
\hline FEV1 mL & $1177 \pm 594$ & $1131 \pm 460$ & $1176 \pm 571$ & $1080 \pm 568$ & $1092 \pm 564$ & 0.71 & 0.59 \\
\hline FEV $1 \%$ pred & $38 \pm 19$ & $39 \pm 16$ & $42 \pm 19$ & $39 \pm 20$ & $39 \pm 20$ & & \\
\hline TLC mL & $2646 \pm 1081$ & $2768 \pm 1151$ & $2880 \pm 1599$ & $2785 \pm 1161$ & $2878 \pm 1202$ & 1.39 & 0.26 \\
\hline TLC $\%$ pred & $46 \pm 16$ & $46 \pm 17$ & $52 \pm 21$ & $50 \pm 17$ & $50 \pm 18$ & & \\
\hline FRC mL & $1643 \pm 750$ & $1498 \pm 612$ & $1726 \pm 901$ & $1567 \pm 508$ & $1634 \pm 564$ & 0.64 & 0.64 \\
\hline FRC \% pred & $53 \pm 20$ & $51 \pm 19$ & $56 \pm 25$ & $51 \pm 13$ & $54 \pm 14$ & & \\
\hline FEV1/FVC \% & $102 \pm 11$ & $100 \pm 8$ & $101 \pm 8$ & $103 \pm 7$ & $91 \pm 17$ & 0.71 & 0.59 \\
\hline MIP kPa & $3.6 \pm 1.1$ & $3.5 \pm 1.2$ & $3.8 \pm 1.2$ & $4.1 \pm 1.5$ & $4.1 \pm 1.6$ & 0.83 & 0.52 \\
\hline MIP \% pred & $45 \pm 21$ & $48 \pm 24$ & $49 \pm 21$ & $47 \pm 23$ & $50 \pm 22$ & & \\
\hline MEP kPa & $5.9 \pm 3.0$ & $6.0 \pm 3.3$ & $6.1 \pm 3.7$ & $6.3 \pm 3.4$ & $6.4 \pm 3.6$ & 0.34 & 0.85 \\
\hline MEP \% pred & $51 \pm 34$ & $59 \pm 35$ & $56 \pm 33$ & $53 \pm 35$ & $52 \pm 23$ & & \\
\hline $\begin{array}{r}\Delta V^{\prime} \mathrm{E} / \Delta P \mathrm{ET}^{2} \mathrm{CO}_{2} \\
\mathrm{~L} \cdot \mathrm{min} \cdot \mathrm{kPa}^{-1}\end{array}$ & $1.33 \pm 0.94$ & $2.69 \pm 1.30^{*}$ & $2.45 \pm 1.18$ & $4.22 \pm 1.77$ & $5.89 \pm 5.08$ & 6.10 & 0.006 \\
\hline$V^{\prime} \mathrm{E}-60 \mathrm{~L}$ & $9.6 \pm 3.1$ & $11.4 \pm 2.8^{*}$ & $14.1 \pm 3.7$ & $16.4 \pm 1.1 *$ & $15.7 \pm 2.9$ & 4.66 & 0.017 \\
\hline$P \mathrm{a}, \mathrm{O}_{2} \mathrm{kPa}$ & $8.1 \pm 1.1$ & $9.4 \pm 1.3 * *$ & $10.2 \pm 1.4^{*}$ & $10.4 \pm 0.9$ & $9.8 \pm 1.4$ & 12.9 & 0.001 \\
\hline $\mathrm{Pa}_{2} \mathrm{CO}_{2} \mathrm{kPa}$ & $7.3 \pm 0.9$ & $6.1 \pm 0.4 * *$ & $5.7 \pm 0.6 * *$ & $5.5 \pm 0.7$ & $5.5 \pm 0.1$ & 14.9 & 0.001 \\
\hline$P A-a, O_{2} \mathrm{kPa}$ & $2.4 \pm 1.2$ & $2.6 \pm 1.4$ & $2.3 \pm 1.7$ & $2.4 \pm 1.0$ & $2.9 \pm 2.5$ & 0.40 & 0.87 \\
\hline$\left[\mathrm{HCO}_{3}^{-}\right] \mathrm{mmol} \cdot \mathrm{L}^{-1}$ & $32 \pm 2$ & $28 \pm 1 * *$ & $27 \pm 2$ & $27 \pm 2$ & $27 \pm 3$ & 10.5 & 0.001 \\
\hline
\end{tabular}

Values are presented as mean \pm SD. VC: vital capacity; RV: residual volume; FEV1: forced expiratory volume in one second; FRC: functional residual capacity; MIP: maximal inspiratory pressure; MEP: maximal expiratory pressure; $\mathrm{Pa}_{\mathrm{a}} \mathrm{O}_{2}$ : arterial oxygen tension; $\mathrm{Pa}_{\mathrm{a}} \mathrm{CO}_{2}$ : arterial carbon dioxide tension; FEV1/FVC: ratio between FEV1 and the forced vital capacity (FVC); TLC: total lung capacity; $\Delta V^{\prime} \mathrm{E} / \Delta P \mathrm{ET}, \mathrm{CO}_{2}$ : is the slope of minute ventilation $\left(V^{\prime} \mathrm{E}\right)$ versus end tidal carbon dioxide tension $\left(P \mathrm{ET}, \mathrm{CO}_{2}\right) ; V^{\prime} \mathrm{E}-60: V^{\prime} \mathrm{E}$ value at a $P \mathrm{ET}, \mathrm{CO}_{2}=8 \mathrm{kPa}(60 \mathrm{mmHg}) . *$ : $<<0.05$; and $* *: \mathrm{p}<0.01$ (Bonferroni tests). 
3 and $4(6-16 \%, 11 \pm 6 \%$, mean $\pm \mathrm{SD})$ and of rapid eye movement (REM) sleep (10-27\%, 15 $\pm 6 \%$, mean \pm SD), demonstrated that sleep architecture was disrupted in this population [22]. Similarly sleep efficiency was reduced and ranged $50-83 \%(74 \pm 10 \%$, mean $\pm \mathrm{SD})$.

\section{Effects of nocturnal IPPV}

Patients reported a mean use of IPPV of $8 \pm 3 \mathrm{~h}$ (ranging 5-12 h) per night. No major complications related to nasal mask or tracheostomy were observed.

As shown in table 2 (see also fig. 1), after nocturnal IPPV, as compared with baseline, pulmonary volumes, respiratory muscle function and $\mathrm{PA}-\mathrm{a}, \mathrm{O}_{2}$ remained relatively unchanged. By contrast, $\mathrm{Pa}_{\mathrm{a}} \mathrm{CO}_{2}$ and $\left[\mathrm{HCO}_{3}{ }^{-}\right]$significantly decreased (at peak effect, $-23 \%$ and $-18 \%$, respectively) and $\mathrm{Pa}, \mathrm{O}_{2}$ increased (at peak effect, $+28 \%$ ). Similarly, as compared with baseline, after nocturnal IPPV, the ventilatory response to $\mathrm{CO}_{2}$ was improved, $\Delta V^{\prime} \mathrm{E} / \Delta P \mathrm{ET}, \mathrm{CO}_{2}$ increasing by $+340 \%$ (at peak effect).

As shown in table 3, as compared with baseline, after nocturnal IPPV, respiratory events during sleep were significantly reduced with, at peak effect, a decrease of $-92 \%$ for the RDI, and $-94 \%$ for the amount of time spent with an $\mathrm{Sa}_{\mathrm{a}} \mathrm{O}_{2}$ below $90 \%$ and an increase of $+6 \%$ for mean $\mathrm{Sa}_{\mathrm{a}} \mathrm{O}_{2}$. Simultaneously, nocturnal IPPV was associated with an improvement of sleep architecture as witnessed by the
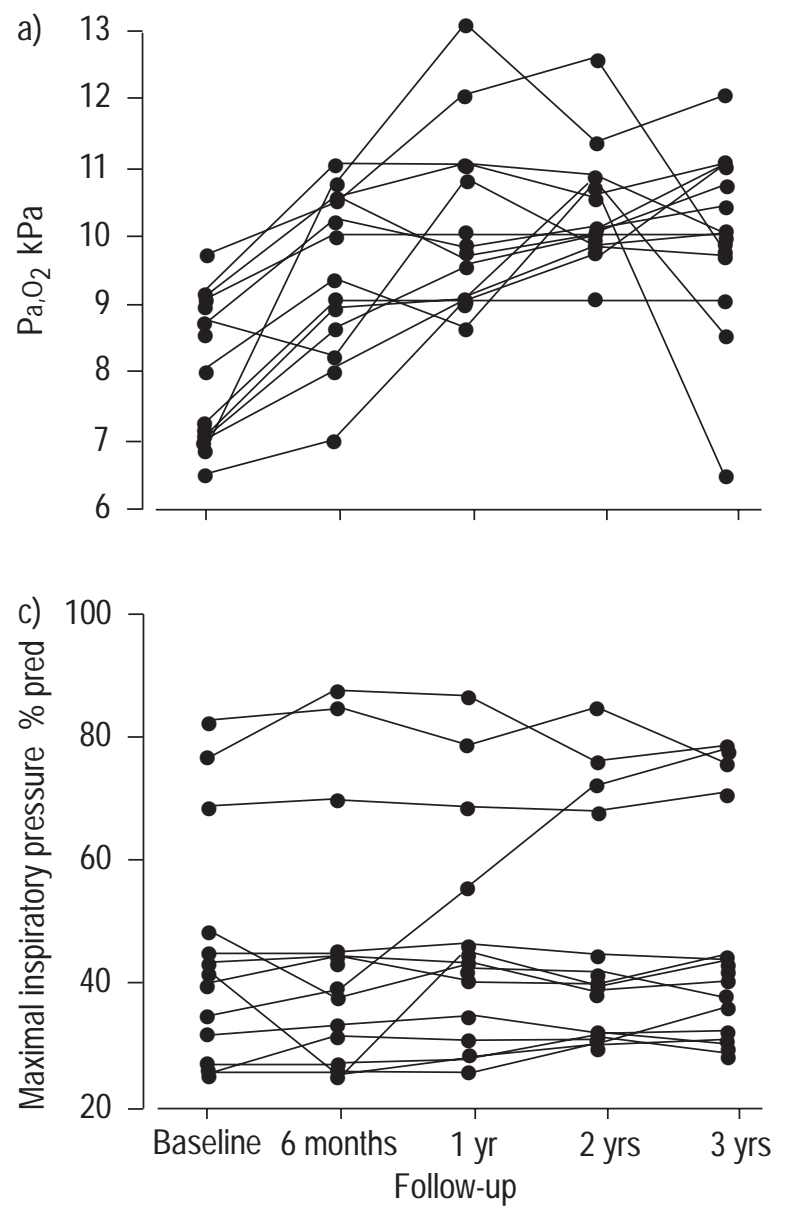

reduction of stages 1 and 2 duration (at peak effect, $-10 \%$ ) and by the increase in the time spent in stages 3 and 4 (at peak effect, $+84 \%$ ) and in sleep efficiency (at peak effect, $+21 \%$ ).

The reduction of diurnal $P \mathrm{a}, \mathrm{CO}_{2}$ correlated with the increase of $\Delta V^{\prime} \mathrm{E} / \Delta P \mathrm{ET}, \mathrm{CO}_{2}(\mathrm{r}=-0.68, \mathrm{p}=0.008)$ (fig. 2). By contrast, the reduction of diurnal $P \mathrm{a}, \mathrm{CO}_{2}$ did not correlate with the changes in MIP (fig. 3).

\section{Discussion}

This study was aimed at evaluating the potential mechanisms for diurnal $P \mathrm{a}, \mathrm{CO}_{2}$ improvement in neuromuscular patients receiving long-term nocturnal IPPV. As previously described, IPPV was easy to implement and was associated with a substantial improvement in alveolar hypoventilation during both night and daytime [1-6]. Furthermore, this study shows, in keeping with previous reports $[6,23]$ that in stable patients nocturnal IPPV effects may be prolonged after a very long period of ventilation.

The respiratory pump mechanics remained stable in each patient throughout the study follow-up. This observation confirms that the patients enrolled in this study have very slowly progressive disease. Thus, it seems very unlikely that the improvement in daytime arterial blood gases were related to improved lung mechanics. This result is in line with previous studies $[2,6,24]$.
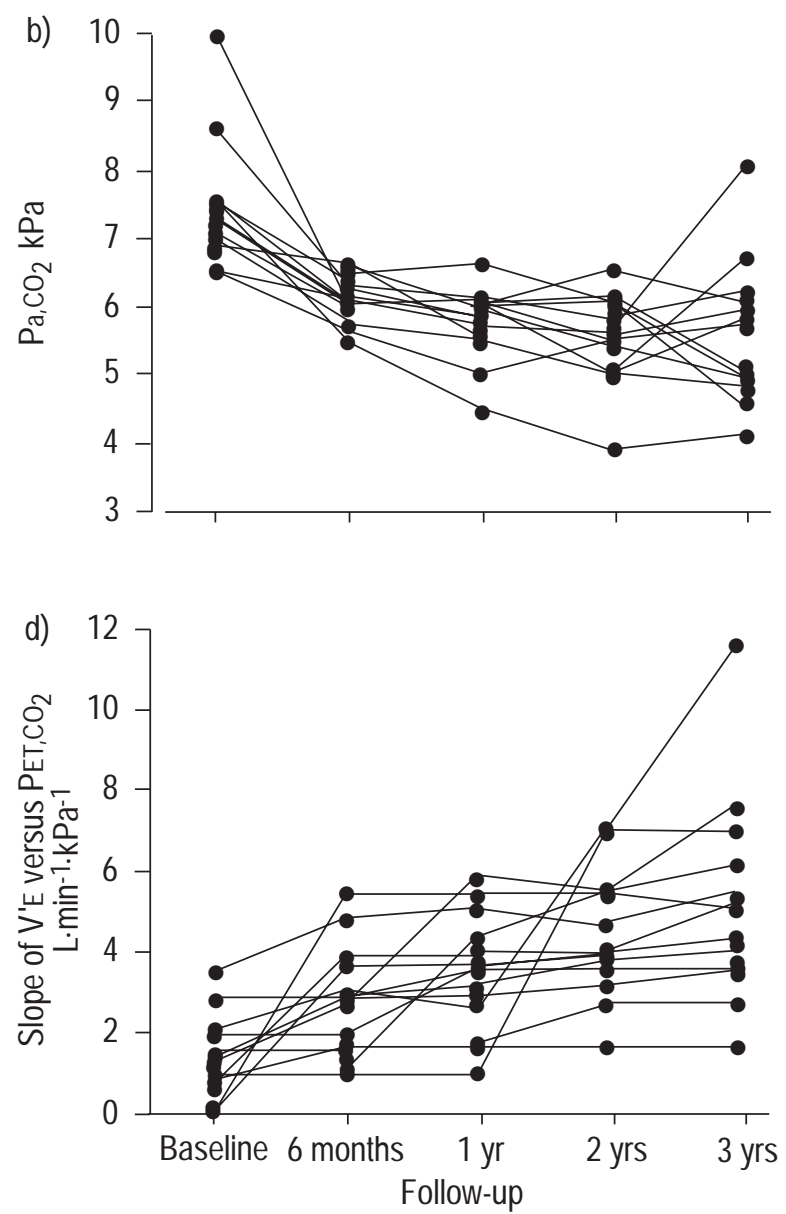

Fig. 1. - The variations of arterial oxygen tension $\left(\mathrm{Pa}_{\mathrm{a}} \mathrm{O}_{2} ; \mathrm{a}\right)$, arterial carbon dioxide tension $\left(\mathrm{Pa}_{\mathrm{a}} \mathrm{CO}_{2} ; \mathrm{b}\right)$, maximal inspiratory pressure $(\mathrm{c})$ and slope of minute ventilation $\left(V^{\prime} \mathrm{E}\right)$ versus end tidal carbon dioxide tension $\left(P \mathrm{ET}, \mathrm{CO}_{2} ; \mathrm{d}\right)$ are given for each of the 14 patients. 


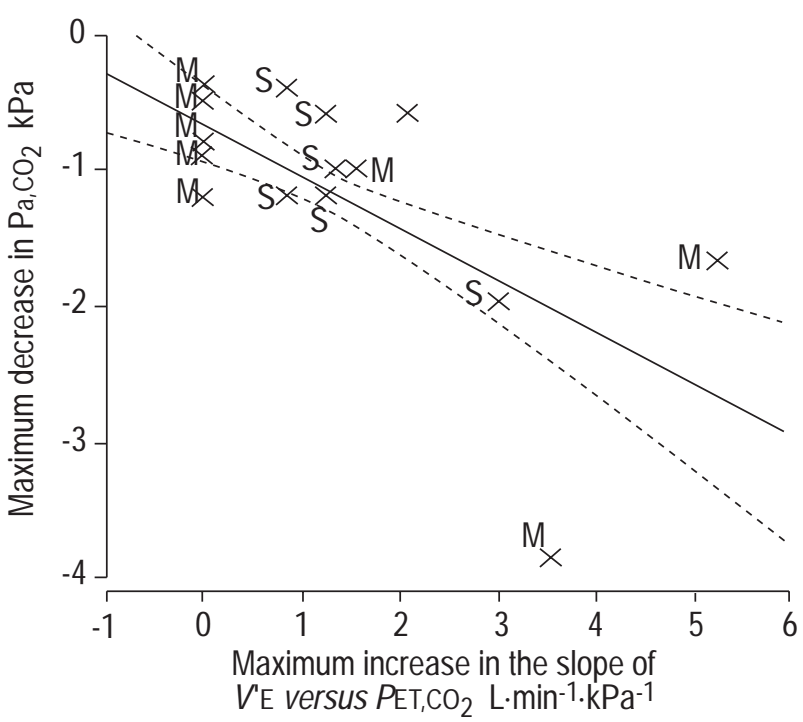

Fig. 2. - The maximum decrease in arterial carbon dioxide tension $\left(\mathrm{Pa}_{\mathrm{a}} \mathrm{CO}_{2}\right)$ was significantly related to the maximum increase of the slope of minute ventilation $\left(V^{\prime} \mathrm{E}\right)$ versus end tidal carbon dioxide tension $\left(P \mathrm{ET}, \mathrm{CO}_{2}\right)(\mathrm{n}=14, \mathrm{r}=0.68$ and $\mathrm{p}=0.008)$. The dependence between the two variables appeared similar in patients with myopathy $(M ; n=8)$ and in those with scoliosis $(S ; n=6)$. The regression line ( - ) with the $95 \%$ confidence interval ( - - ) are given. (For further explanation see text.)

In chronic neuromuscular disorders, maximal static inspiratory and expiratory mouth pressure measurement is conventionally used to assess respiratory muscle strength $[25,26]$. However, these tests require patient's volition and may be less accurate than transdiaphragmatic pressure measurement during electric or magnetic phrenic nerve stimulation. No significant change in maximal static mouth pressures were noted throughout the study period, as previously observed in neuromuscular diseases [6, 19] and contrary to COPD patients [8-11]. Although we did not use nonvolitional tests, it seems very unlikely that the improvement in daytime arterial blood gases is related to an improved respiratory muscle strength.

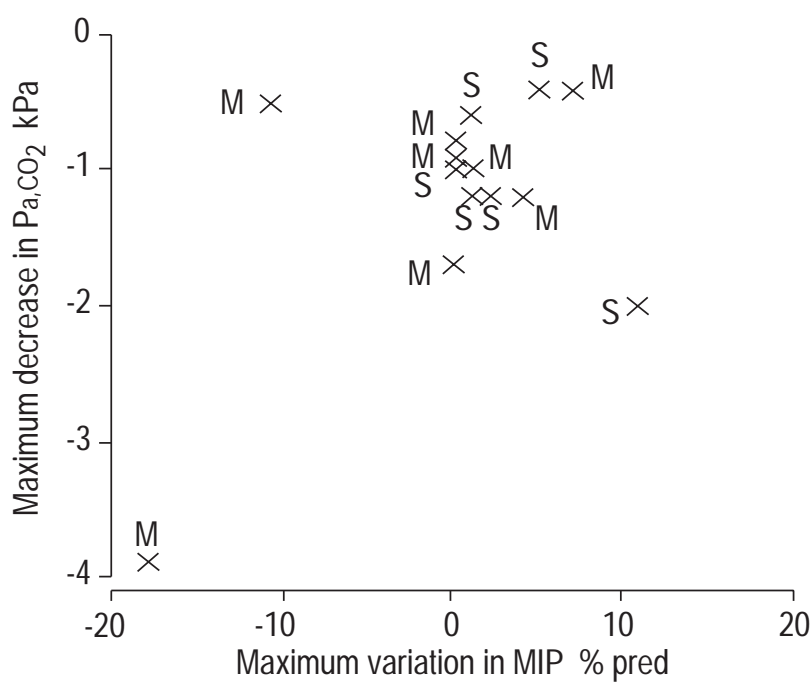

Fig. 3. - The maximum decrease in arterial carbon dioxide tension $\left(P \mathrm{a}, \mathrm{CO}_{2}\right)$ was not related to the maximum variation of maximal inspiratory pressure (MIP) in the whole population $(n=14)$, in patients with myopathy $(\mathrm{M} ; \mathrm{n}=8)$ and in those with scoliosis $(\mathrm{S} ; \mathrm{n}=6)$. (For further explanation see text.)
In this study, the patients had a substantial increase in mismatching of ventilation to perfusion in the lung, as depicted by the high $P$ A-a, $\mathrm{O}_{2}$ values. These values are very close to those previously reported in neuromuscular patients $[6,15]$. Although a slight decrease in the $P A-a, O_{2}$ was observed after IPPV, the difference with baseline values failed to reach a level of statistical significance. Thus, as previously suggested [6], in chronic neuromuscular patients receiving nocturnal IPPV, the improvements in daytime arterial blood gases were probably not related to a reduction in ventilation-perfusion mismatching.

Numerous studies demonstrated that the ventilatory response to $\mathrm{CO}_{2}$ is blunted in neuromuscular and thoracic cage disorders [15, 27-29]. Our data corroborate the findings from these studies and demonstrate that night-time IPPV improves the ventilatory response to $\mathrm{CO}_{2}$. Moreover, the changes in slope of ventilatory response to $\mathrm{CO}_{2}$ were found to be correlated with the changes in daytime $P \mathrm{a}, \mathrm{CO}_{2}$. In theory, the improvement in ventilatory response to $\mathrm{CO}_{2}$ may be related to improved respiratory muscle strength, improved lung compliance or improved respiratory drive. In practice, in this study, no change in respiratory muscle strength or in pulmonary compliance could be observed, thus it seems likely that improved respiratory drive was accounted for by the observed increase in ventilatory response to $\mathrm{CO}_{2}$. Although the inspiratory occlusion pressure after $0.1 \mathrm{~s}$ was not recorded in this study, it is suggested that the improvement of daytime hypoventilation was due to the improvement in central respiratory drive.

The change in ventilatory response to $\mathrm{CO}_{2}$ rebreathing has also been observed in patients with obstructive sleep apnoea treated with nasal continuous positive airway pressure or after tracheostomy [30-32]. It is generally admitted that this improvement represents adaptation of the central chemoreceptors to the reduction of hypercapnia overnight or alternatively reflects changes in the quality of sleep, since sleep deprivation results in a significant deterioration of hypercapnic ventilatory responses [33, 34]. Interestingly, important sleep-disordered breathing and sleep disruption were observed in this population, which met the criteria of severe obstructive and/or central sleep apnoea [35] and which were reversed by IPPV. Therefore, it was assumed that, as in severe sleep apnoea syndrome, sleep-disordered breathing observed in this population is a potentially critical component in the decrease of the central respiratory drive and therefore in the pathogenesis of daytime arterial hypercapnia. In addition, this hypothesis explained why the pathogenesis of daytime arterial hypercapnia is different in our population and in COPD patients. It has been demonstrated that sleep abnormalities with several arousals and long periods of wakefulness are generally present in patients with severe COPD [36]. However, these phenomenon and therefore the beneficial effects of positive pressure ventilation are generally less important [37] than were observed in this population.

In conclusion, prolonged nocturnal intermittent positive pressure ventilation results in improved chronic hypoventilation during daytime spontaneous ventilation in patients with neuromuscular or chest wall diseases. These data do not support the hypothesis that this improvement was due to a relief of muscle fatigue or to an improvement in lung mechanics. However, because the increase in daytime arterial carbon dioxide tension is correlated with an increase of ventilatory response to carbon dioxide rebreathing and 
is associated with an improvement of severe sleep-disordered breathing, this supports the fact that hypercapnia in neuromuscular or chest-wall diseases is due to a decrease in central respiratory drive, and that improvement of daytime hypoventilation with nocturnal intermittent positive pressure ventilation may represent adaptation of the central chemoreceptors to the reduction of profound hypercapnia during sleep and/or reflect change in quality of sleep.

\section{References}

1. Hoeppner VH, Cockcroft DW, Dosman JA, Cotton DJ. Night-time ventilation improves respiratory failure in secondary kyphoscoliosis. Am Rev Respir Dis 1984; 129: 240-243.

2. Ellis ER, Bye PTP, Bruderer JW, Sullivan CE. Treatment of respiratory failure during sleep in patients with neuromuscular disease. Positive-pressure ventilation through a nose mask. Am Rev Respir Dis 1987; 135: 148-152.

3. Bach JR, Alba A, Mosher R, Delaubier A. Intermittent positive pressure ventilation via nasal access in the management of respiratory insufficiency. Chest 1987; 92: 169170.

4. Carroll N, Branthwaite MA. Control of nocturnal hypoventilation by nasal intermittent positive pressure ventilation. Thorax 1988; 43: 349-353.

5. Heckmatt JZ, Loh L, Dubowitz V. Night-time nasal ventilation in neuromuscular disease. Lancet 1990; 335: 579582.

6. Barbé F, Quera-Salva MA, de Lattre J, Gajdos Ph, Agusti AGN. Long-term effects of nasal intermittent positivepressure ventilation on pulmonary function and sleep architecture in patients with neuromuscular diseases. Chest 1996; 110: 1179-1183.

7. Shneerson J. The changing role of mechanical ventilation in COPD. Eur Respir J 1996; 9: 393-398.

8. Gutierrez M, Beroiza T, Contreras G. Weekly cuirass ventilation improves blood gases and inspiratory muscle strength in patients with chronic airflow limitation and hypercarbia. Am Rev Respir Dis 1998; 138: 617-623.

9. Cropp A, Dimarco A. Effects of intermittent negative pressure ventilation on respiratory muscle function in patients with severe chronic obstructive pulmonary disease. Am Rev Respir Dis 1987; 135: 1056-1061.

10. Celli B, Lee H, Criner G, et al. Controlled trial of external negative pressure ventilation in patients with severe chronic airflowlimitation. AmRevRespirDis 1989;140:1251-1256.

11. Scano G, Gigliotti F, Duranti R, Spinelli A, Gorini M, Schiavina $M$. Changes in ventilatory muscle function with negative pressure ventilation in COPD. Chest 1990; 97: 322-327.

12. Elliott M, Mulvey D, Moxham J, Green M, Branthwaite M. Domiciliary nocturnal nasal intermittent positive pressure ventilation in COPD: mechanism underlying changes in arterial blood gas tensions. Eur Respir J 1991; 4: 1044-1052.

13. Goldstein RS, De Rosie JA, Avendano MA, Dolmage TE. Influence of non-invasive positive pressure ventilation on inspiratory muscles. Chest 1991; 99: 408-415.

14. Marino W, Braun NMT. Reversal of the clinical sequaele of respiratory muscle fatigue by intermittent mechanical ventilation. Am Rev Respir Dis 1980; 122: 617-621.

15. Loh L, Hughes JMB, Newson Davis J. Gas exchange problems in bilateral diaphragm paralysis. Bull Eur Physiopath Respir 1979; 15: 137-141.

16. American Thoracic Society. Standardization of spirometry: 1987 update. Am Rev Respir Dis 1987; 136: 1285-1298.
17. Black LF, Hyatt RE. Maximal static respiratory pressures in generalized neuromuscular disease. Am Rev Respir Dis 1971; 103: 641-650.

18. Adler JJ. A simplified method for evaluating the ventilatory response to carbon dioxide. Am Rev Respir Dis 1973; 108: 1449-145.

19. Read DJC. A clinical method for assessing the ventilatory response to $\mathrm{CO}_{2}$. Aust Ann Med 1966; 16: 20-31.

20. Rechtschaffen A, Kales A. A Manual of Standardized Terminology Techniques and Scoring Systems for Sleep Stages. Washington, DC, US Government Printing Office, 1968.

21. Moser NJ, Phillips BA, Berry DTR, Harbison L. What is hypopnea, anyway? Chest 1994; 105: 426-428.

22. Williams RL, Karacan I, Hursch CJ. Electroencephalography of Human Sleep: Clinical Applications. New York, Wiley, 1974.

23. Garray SM, Turino GM, Goldring RM. Sustained reversal of chronic hypercania in patients with alveolar hypoventilation syndromes. Long term maintenance with non invasive nocturnal mechanical ventilation. Am J Med 1981; 70: 269-274.

24. Kerby GR, Mayer LS, Pingleton SK. Nocturnal positive pressure ventilation via nasal mask. Am Rev Respir Dis 1987; 135: 738-740.

25. Vincken W, Elleker MG, Cosio MG. Determinants of respiratory muscle weakness in stable chronic neuromuscular disorders. Am J Med 1987; 82: 53-58.

26. De Troyer A. The respiratory muscles. In: Crystal RG, West JB, Weibel ER, Barnes PJ, eds. The Lung: Scientific Foundation. Philadelphia, Lippincott Raven, 1997; pp. 1203-1217.

27. Riley DJ, Santiago TV, Daniele RP, Scall B, Edelman NH. Blunted respiratory drive in congenital myopathy. $\mathrm{Am} \mathrm{J}$ Med 1977; 63: 459-466.

28. Weng TR, Schultz GE, Chang CH, Nigro MA. Pulmonary function and ventilatory response to chemical stimuli in familial myopathy. Chest 1985; 88: 488-495.

29. Bergofsky E. Respiratory failure in disorders of the thoracic cage. Am Rev Respir Dis 1979; 119: 643-669.

30. Guilleminault C, Cummiskey J. Progressive improvement in apnea index and ventilatory response to $\mathrm{CO}_{2}$, after tracheostomy in obstructive sleep apnea syndrome. $\mathrm{Am}$ Rev Respir Dis 1982; 126: 14-20.

31. Sullivan CE, Issa F. Pathophysiological mechanisms in obstructive sleep apnea. Sleep 1980; 3: 235-246.

32. Berthon-Jones M, Sullivan CE. Time course of change in ventilatory response to $\mathrm{CO}_{2}$ with long-term of CPAP therapy for obstructive sleep apnea. Am Rev Respir Dis 1987; 135: 144-147.

33. Cooper KR, Phillips BA. Effect of short-term sleep loss on breathing. J Appl Physiol 1982; 53: 855-858.

34. White DP, Douglas NJ, Pickett CK, Zwillich CW, Weil JV. Sleep deprivation and the control of ventilation. $\mathrm{Am}$ Rev Respir Dis 1983; 128: 984-986.

35. Quera Salva MA, Guilleminault C, Partinen M, Jamieson A. Determinants of respiratory disturbance and oxygen saturation drop indices in obstructive sleep apnoea syndrome. Eur Respir J 1988; 1: 626-631.

36. Douglas NJ, Flenley DC. Breathing during sleep in patients with obstructive lung disease. Am Rev Respir Dis 1990; 141: 1055-1070.

37. Elliot MW, Simonds AK, Carroll MP, Wedzicha JA, Branthwaite MA. Domiciliary nocturnal nasal intermittent positive pressure ventilation in hypercapnic respiratory failure due to chronic obstructive lung disease: effects on sleep and quality of life. Thorax 1992; 47: 342-348. 